\title{
Assessing the Implementation of Teachers' Community (MGMP) as a Medium for Ongoing Professional Development to Enhance English Teachers' Professional Competence
}

\author{
Syaifuddin Iskandar \\ Faculty of Social and Political Sciences \\ Samawa University \\ Sumbawa Besar, Indonesia \\ syaifuddiniskandar@gmail.com
}

\author{
Darmanto Darmanto* \\ Faculty of Social and Political Sciences \\ Samawa University \\ Sumbawa Besar, Indonesia \\ darmanto@universitas-samawa.ac.id
}

\author{
Erma Suryani \\ Faculty of Teacher Training and \\ Education \\ Samawa University \\ Sumbawa Besar, Indonesia \\ suryanierma793@gmail.com
}

\begin{abstract}
The Indonesian government has provided several teachers' professional development programs for the last few years. Those programs are provided to enhance teachers' competencies. Teachers' community (MGMP, henceforth) is one of them. This study aims at describing: 1) the teachers' perceptions about their competencies after participating in MGMP, 2) the implementation of MGMP to enhance English teachers' competencies, 3) the hindering factors influence their participation in MGMP. The design of this study was descriptive qualitative. The subjects were the English teachers, committee, and coordinator of the Central Zone Junior High school English teacher MGMP in Selong, East Lombok, a committee, and a coordinator of the MGMP. In collecting the data, the following procedures were applied: interview, observation, and documentation. The results showed that all of the subjects provided positive views on the implementation of MGMP. The participants perceived that MGMP enhanced their competencies. The results also showed that the implementation of MGMP worked effectively. Meanwhile, the schedule and the rolling system were the hindering factors influence teachers' participation in MGMP.
\end{abstract}

Keywords-Teachers' Community, professional development, and competence

\section{INTRODUCTION}

Professional development programs are systematic efforts that aim at bringing the change to the teachers in their classroom practices, their attitudes and beliefs, and the student learning outcomes (Guskey), [1]. Nowadays, several teachers' professional development programs have provided by the Indonesian government. One of those professional development programs is Teachers' Community (MGMP). MGMP is a continuous strengthening of teacher professional quality improvement which is one of the components of the BERMUTU (Better Education through Reformed Management and Universal Teacher Upgrading) program. This program is one of the programs of the DITGEN QINTEP of the Ministry of Education and Culture which aims to improve learning mechanisms (Informasi Guru, 2017), [2]. Teacher communities can be defined as groups of teachers who continually inquire into their practice that aims to discover, create, and negotiate new meanings that improve their practice (NCTE), [3]. By involving in these programs, teachers are expected to expand their knowledge and skills in order to be able to implement the best possible practices because simply educators learn to help students learn at the highest levels (Mizell), [4]. The case is many teachers still face problems in implementing the curriculum in their practices even though they have been involved in a number of professional development programs.

Waluyo and Soepriyanti [5] identify three problems that concern with the impact of the implementation of the current curriculum to teachers' professional practices. Firstly, teachers experienced difficulties to transform their experiences into practice because the professional development provided did not match with their professional needs. Secondly, there was a wide gap between teachers' common teaching beliefs and the new pedagogical procedures suggested by the curriculum. Teachers were inclined to return to their old teaching practices. Thirdly, there was a need to develop additional textbooks as a supplement for the present core textbook. The present core book was problematic in terms of content and language structure. So, the teachers expected that the curriculum authority considers developing appropriate, interesting supplemental textbooks that stemmed from local, national, and global wisdom. Thus, teachers could have adequate resources for the inclusion of character education in English language teaching.

Referring to such problems mentioned above, the current study intends to assess the implementation of the professional development program, namely MGMP. The current study is conducting to provide the actual data and information related to the teachers' perceptions about their competencies after participating in MGMP, the implementation of MGMP whether it works effectively or not.

Regarding to those purposes, the five modified characteristics of the effective professional development stipulated by Darling-Harmond et al [6] are used as indicators in the current study. By using those indicators, it is expected to reveal whether the MGMP meets the indicators of effective professional development.

Firstly, professional development focuses on active learning that directly engages teachers in designing and trying out teaching strategies. Secondly, professional development emphasizing teachers supports collaboration. 
By working collaboratively, teachers are supposed to obtain knowledge from surrounding teachers to enhance issues that are gradually encountered during teaching and learning in a classroom. The next is employing effective practice modeling (EPM) which is intended for teachers to learn what and how from experienced teachers. In EPM, teachers are doing observation and making the modeling as the teaching reference.

Subsequently, professional development is coaching and expert support. Coaching and expert support involve sharing of expertise ranging from content of teaching to personal teaching experience which focuses considerably on teachers' individual needs. Finallly, professional development offers feedback and reflection. High-quality professional learning frequently provides time for teachers to rethink, receive input from, and make changes to their practice through reflection and feedback.

The Law No. 14 of 2005 Article 10 [7] states that there are four competencies that have to be possessed by professional teachers in Indonesia; pedagogical competence, personality competence, social competence, and professional competence. In the current study, only professional competence is discussed and elaborated.

Professional competence is the ability to master subject matter widely and deeply (The Law No. 14 of 2005). According to the Regulation of the Ministry of the Education and Culture No. 16 of 2007 [8], there are several indicators that can be used to investigate teacher's professional competence: the teachers master the subject matter that they teach, the teachers' ability to choose learning materials that are appropriate to their students' development level, the teachers' ability to reflect on their own performance, the teachers' ability of to follow the progress of the times by learning from various sources, and the teachers' ability of to use information and communication technology for self-development.

\section{RESEARCH METHODOLOGY}

The current study employs qualitative. The current study was conducted at the Central Zone Junior High School English teacher MGMP in Selong, East Lombok. There were eight participants in the current study. In determining the participants, purposive sampling technique was applied. Data collection methods in the current study were observation and interview.

The interviews were conducted in advance with the participants. After getting answers from the participants, the next step was observation. There were two observations carried out in this study, namely teachers' activities in MGMP observation and teachers' classroom observation. The first observation related to the participants' activities in MGMP. Through this observation, the researchers tried to get information and see directly the implementation of MGMP activities. Meanwhile, the second observation was classroom observation. Teachers' classroom observations was carried out to strengthen interviews data about participants' competencies. It aimed to see directly whether the information that was obtained at the the interview is in accordance with the fact.

\section{FINDINGS AND DISCUSSION}

In this part, three core sections are presented. All of those sections relate to the research questions. The first section relates to the participants' perceptions regarding their competencies after participating in MGMP. The second section goes to the implementation of the MGMP. The last section deals with the hindering factors that influence teachers' participation in MGMP.

\section{A. Findings}

The data in this study were obtained from two main sources, namely interviews and observations. Interviews were conducted with eight study participants six English teachers (T1-T6), 1 committee, and 1 MGMP coordinator. However, only four teachers were ready to be observed in their classroom

\section{Participants' Perceptions Regarding to Their Professional Competence after Participating in MGMP}

All participants who were interviewed during this study informed that their participation in MGMP has greatly influenced their competencies. Participants also acknowledged that their competencies enhanced after attending the MGMP. For example, T2 expressed his thought, "My participation in MGMP helped me greatly in enhancing my knowledge and skills as a teacher. I gained additional knowledge. Discussion and sharing of experiences in MGMP enriched my experience as a teacher. In the same manner, T3 asserted "my participation in MGMP strongly helped enhancing my knowledge and skills as a teacher". Furthermore, T4 a novice teacher contended "I felt that there was a significant improving in my competencies after I joined MGMP. My participation in MGMP also changed my perspective and attitude in implementing learning in the classroom. Meanwhile T5, a senior teacher stated "as a senior teacher I was greatly helped because I might still often use the old patterns in teaching". Furthermore, CM explained that "English teachers were greatly helped by the existence of MGMP because this is in line with our expectation to form this forum. The point is to create teachers who are independent, creative, and innovative.

Referring to the results of interviews and observations, I inferred that The Central Zone Junior High School English teacher MGMP in Selong, East Lombok MGMP enhanced the participants' competencies in general. Even though, there was a fact that showed a teacher who could not teach well. The participants acknowledged that their competencies enhanced after participating in MGMP. The discussions and sharing ideas among the participants strongly helpful for them.

\section{The Effectivenes of the Implementation of MGMP}

In answering the second research question related to the implementation of the Central Zone Junior High School English teacher MGMP in Selong, East Lombok, the researchers explored information from several reliable sources, namely English teachers, committee, and coordinator of the Central Zone Junior High School English 
teacher MGMP in Selong, East Lombok. The researchers also conducted the observation when the teachers attended the MGMP.

The participants of The Central Zone Junior High School English teacher MGMP in Selong, East Lombok stated that MGMP provided the opportunity for participants to actively participate in designing and trying various learning strategies. As stated by T1 "MGMP really provides an opportunity for participants to actively participate in developing and preparing strategies and learning tools, but participants still need guidance especially related to learning models". T3 added "at the beginning of the semester, in MGMP we usually focus on learning strategies. So, we design together. After that, we will present the results in front of the forum ". T4 asserted "MGMP is a place for teachers to create and discuss about how to design various teaching methods and strategies". The observations also show data that are relevant to the participants' information. The participants learned a lot of learning models in MMGP.

In addition to discussing designing various teaching methods and strategies, participants also stated that the MGMP was very helpful, especially in teaching preparation. As stated by T3 "we discussed a lot about tools and learning strategies in MGMP". T4 added "we learned many things at MGMP, for example about the preparation of learning tools". T5 explained "we learned how to draw up a learning plan in accordance with the demands of K13, designing the right according to government regulations". Furthermore, CR added "the participation of participants in MGMP certainly has a positive impact on teachers, especially in terms of teaching preparation. Our teachers are equipped with teaching preparation that contains all the components required by the latest curriculum. The $\mathrm{CM}$ further stated "teachers are very helpful especially in the preparation of learning tools, teaching methodology, teaching media, and all types of other learning tools". The results of observations are very relevant to the information that researchers obtained from the participants. MGMP activities so far had been very focused on the preparation of teaching preparation. All MGMP participants in the Central Zone are really fostered in preparing the learning tools so they had a clear learning plan.

In addition, some participants also stated that the instructors at MGMP were very competent and rich in experience. For example, T1 revealed "MGMP administrators have a lot of experience, especially regarding K13". T4 added "The instructors are very outstanding and competent because they have a lot of experience and often attend various workshops". T5 "the instructors are really smart and experienced". The observations so far have shown that at each MGMP meeting, the participants are always accompanied and assisted by instructors. So, the participants not only discuss with fellow participants but are also guided by instructors so that the discussion becomes directed.

Participants stated that the MGMP also strongly supports collaboration among the participants. For example, T1 informed that "we used to work in groups. All participants jointly set up learning tools, making it easier for us to carry out the task ". T2 added "the collaboration among participants is very good because we have to support each other". Furthermore T3 asserted that "MGMP strongly demands cooperation among the participants. We have to work together because the participants are divided into groups that are responsible for discussing certain basic competencies. After that, the results of the internal group discussion will be presented. Other groups can also provide input on the results of discussions ". T4 contended that "I think the activities in MGMP really support collaborative learning because the participants are required to work together. Every school has a different problem, so we get lots of ideas about how to solve every problem in the classroom". The observations during the MGMP activities also supported the statements delivered by participants about the collaboration among the participants, but the researchers saw that there were some participants who had less motivation in participating in the activities, so that not all activities were expected to run fully. For example, the researchers saw directly that there were some predetermined groups that could not accomplish their group's tasks on time. This was strongly disturbing the activities that have been previously scheduled.

Referring to the data presented above, the researchers inferred that there some key points stated by the participants, such as MGMP provided the opportunity for the participants to actively participate in designing and trying out various learning strategies, learning methods, and preparing the teaching administrations, MGMP supported by the competent instructors, and MGMP strongly supported collaborative learning.

\section{The Hindering Factors Influence Teachers' Participations in MGMP}

The participants informed that their participation in MGMP was still constrained by their teaching schedule. For example, T6 contended "the problem is the schedule of meetings at the MGMP which often clashes with our teaching schedule at school". Furthermore, CM and CR agreed that "sometimes there are some participants who have the teaching schedule that coincides with the MGMP schedule, but it has started well scheduled now".

The participants also recognized that the implementation of the rolling system for English teachers to attend MGMP was an obstacle for them to actively participate in MGMP. As stated by T3 "our school applies a rolling system to participate in MGMP activities".

Referring to the data above, the researchers inferred that all of the English teachers in the Central zone did not have the same chances to participate in MGMP. Teachers' schedules coincided with the MGMP schedule and applying a rolling system for English teachers in several schools to participate in MGMP were two hindering factors that influence the teachers' participation in MGMP.

\section{B. Discussion}

This section presents the findings of the study discussed in the context of the relevant theoretical framework. The findings in this study supported and strengthened the findings of previous studies conducted by Novozhenina \& Pinzon [9] and Permatasari [10] which were used as relevant studies. The results of the two previous studies showed that the professional development program, in this case, MGMP, 
demonstrated positive results. Furthermore, the implementation of MGMP also has a significant effect on teachers' performance.

Referring to the data collected during the study, there are three themes related to the implementation of MGMP. Those are elaborated successively as follow:

\section{MGMP Enhanced English Teachers' Professional Competence}

The participants in the current study, admitted that they were greatly helped by the implementation of MGMP. They acknowledged that there were significant changes and improvements related to their professional competence. Further, they contended that MGMP changed their perspective and attitude in implementing learning in the classroom. This relates to the important role of a professional development program stated by Marcelo [11]. He alludes that professional development sets out to promote changes for the teachers, so they may grow either as professionals or individuals. So, the participants were more motivated to take part in MGMP activities because they believed that they needed the forum for the development and improvement of their competencies. They also believed that MGMP was the right place for them to develop themselves.

\section{The Implementation of MGMP Worked Effectively}

The implementation MGMP in Selong, East Lombok worked effectively. It could be proven by several facts that the MGMP fulfilled some characteristics of effective professional development stipulated by Darling Hamond et al (2017). Those characteristics were:

Firstly, MGMP provided the opportunity for the participants to directly engaged in designing and trying out teaching strategies and learning models. This point included preparing the teaching administration. Grossman et al [12] state that the teachers' community provides an ongoing venue for teacher learning. Furthermore, DITGEN QINTEP [13] states that one of the main purposes of the MGMP is extending the teachers' knowledge in various ways, specifically in preparing and mastering learning materials, learning strategies, learning methods, maximizing the learning facilities, and utilizing learning resources. Teaching preparation and learning models are the two main focuses of the MGMP. Those two focuses are elaborated successively as follow:

Learning Models. One of the most important agenda in MGMP is the participants learn various predetermined learning models. As we know, that the standard process of implementing primary and secondary education has been determined in the Regulation of the Minister of Education and Culture No. 23 of 2016 [14]. The Process Standard states that learning applies Scientific Approaches which are supported by various learning methods such as inquiry/discovery learning, problem-based learning, and project-based learning.

In K13, the learning process should be carried out interactively, inspirational, fun, challenging, motivating students to participate actively, as well as providing sufficient space for initiative, creativity, and independence in accordance with the talents, interests, and physical and psychological development of students (Directorate of Secondary School Development), [15].

Furthermore, there are several learning principles demanded by K13, including the learning process shifting from students being told to learners to find out, from the teacher as the only source of learning to learning based on various learning resources, and from the textual approach to the process as reinforcement use of scientific approaches .

Teaching preparation. Besides learning about teaching models, the participants in MGMP actively arranged their teaching preparation. We cannot deny that the occurrence of curriculum changes that have occurred repeatedly in the education system prevailing in Indonesia, definitely demands the teachers' ability to always adapt to what is required by the curriculum. This is absolutely necessary because each curriculum has different characteristics. One thing that is strongly different from each curriculum certainly lies in the approach applied by the curriculum.

One of the things that must be considered by teachers is how they arrange lesson plans that are in line with curriculum demands. K13, the latest curriculum in Indonesia, demands lesson plan to improve the efficiency and effectiveness of the achievement of graduate competencies. Participants in this study acknowledged that they were greatly helped by the existence of the MGMP. They explained that they were truly equipped with the ways to develop lesson plan that were in line with curriculum demands. The MGMP is really focused on preparing lesson plans at the beginning of each semester, so that when entering the new school year, the participants, the English teacher, are ready to apply what they have compiled and learned during the MGMP.

Secondly, MGMP employed effective practice modeling and coaching. Effective practice modeling provided teachers with a clear vision of what best practices look like. In this case, the MGMP supported by competent instructors. Two instructors were appointed and trained in the Institute for Educational Quality Assurance (LPMP) of Nusa Tenggara Barat province. Thirdly, MGMP supported collaborative learning. Collaborative learning allows the participants to engage and involve themselves more actively in the learning process. It gives them a chance to learn their strengths and weaknesses as they work in groups.

\section{Two Hindering Factors Influence the Teachers' Participation in MGMP}

There were two main problems that were found out and become the hindering factors that affected teachers' participation in the MGMP. The first factor, some schools still scheduled English teachers to teach coincided with the MGMP schedule. The teachers of these schools had to teach in their schools before attending the MGMP. Absolutely, they could not attend the MGMP on time. The second factor is some schools applied a rolling system for English teachers to attend MGMP. 


\section{CONCLUSION}

MGMP obviously plays an important role as a medium for ongoing professional development to enhance teachers' competencies in Indonesia. Broadly speaking, it can be concluded as follows:

Firstly, the participants of the current study perceived that their participation in MGMP enhanced their professional competence. MGMP significantly helped the teachers in improving their competence because they learned many things related to the improvement and development of teacher abilities as professional instructors. For example, in MGMP all participants are equipped and mentored in developing teaching preparation and learning models.

Secondly, the implementation MGMP in Selong worked effectively. It could be seen from the implementation of MGMP that focusing on active learning, supported collaborative learning among the participants, employed effective practice modeling, and coaching and expert support.

Thirdly, there were two factors that hinder teachers' participation to be involved in MGMP. Firstly, several schools still scheduled English subjects to coincide with the schedule of the MGMP. Secondly, several schools applied a rolling system for English teachers to participate in MGMP.

\section{REFERENCES}

[1] Guskey, T. R. (2002). Professional Development and Teacher Change. Teacher and Teaching: theory and practice, 8 (3/4).

[2] Informasi Guru. (2017). Standar Pengembangan dan Rambu-Rambu KKG/MGMP. Retrieved from http://www.informasiguru.com/2017/02/DownloadPanduan-KKGMGMP-KKKS.html. on 12 February 2019.

[3] National Council of Teachers of English. (2010). Teacher Learning Communities.

[4] Mizell, H. (2010). Why Professional Development Matters. United States of America: Learning Forward.

[5] Waluyo, U., \& Soepriyanti, H. (2018). The Impacts of In-service Teacher Professional Training on the Development of Teachers' Pedagogical Content Knowledge: Insights from Junior High School Teachers in Mataram, Lombok, Indonesia. The $65^{\text {th }}$ TEFLIN International Conference, 65 (1): 404-409.

[6] Darling-Hammond et al . (2017). Effective Teacher Professional Development. Palo Alto, CA: Learning Policy Institute.

[7] The Law No. 14 of 2005.

[8] The Regulation of the Ministry of Education and Culture No. 16 of 2007.

[9] Novozhenina, A., \& Pinzon, M. M. L. (2018). Impact of a Professional Development Program on EFL Teachers' Performance. HOW, 25 (2): 113-128.

[10] Permatasari, A. N. (2016). The Effectiveness of Teachers' Community on Junior High School Teachers' Performance in Pandaan.

[11] Marcelo, C. (2009). Professional Development of Teachers: Past and Future. Sisifo. Educational Sciences Journal, (8): 5-20.

[12] Grossman, P et al . (2001). Toward a Theory of Teacher Community. Teachers College Record, 103 (6): 942-1012.

[13] DITGEN QITEP. (2008). Standar Pengembangan: Kelompok Kerja Guru (KKG) \& Musyawarah Guru Mata Pelajaran (MGMP).

[14] The Regulation of the Ministry of Education and Culture No. 23 of 2016

[15] Directorate of Secondary School Development. (2016). Panduan Pembelajaran untuk Sekolah Menengah Pertama. 